\title{
Emerging and eco-friendly approaches for waste management: a book review
}

\author{
Anil Kumar Singh ${ }^{1,2}$ and Abhay Raj ${ }^{1,2^{*}}$ (1)
}

\begin{abstract}
Apart from fulfilling the demand of society, the industrial sector, including paper, tannery, distillery, and textile, plays an essential role in manufacturing of the products while, such all still emitting hazardous contaminants to the environment during manufacturing operation. Significant contaminants, including PAHs, EDCs, Dyes, and POPs, are the primary ingredients of wastewater and sludge emitted from such industries. Such contaminants seem to have a carcinogenic, cytotoxic, and mutagenic toxicity endpoints. As a consequence, the long-term presence of such contaminants has led to severe environmental and human impacts. Therefore, it is necessary to tackle such issues to clean-up contaminants and to ensure environmental protection by reducing the toxicity of such contaminants. Here we review the book "Emerging and Eco-Friendly Approaches for Waste Management" for addressing waste management techniques in an eco-friendly manner. In this collection, different approaches, including specific unique plantbased methods for bioremediation, endophytes, and a specific number of micro-organisms, have been reported for decolorization of toxic textile dyes, along with biodegradation of different phenolic, chlorinated, lignin, and its derived compounds. Besides the conventional treatment techniques for clean-up of lignin, lignin-derived compounds, PAHs, chlorinated phenol compounds, EDCs, a certain number of methods in an eco-friendly manner are also explored for remediation, and mitigation of such pollutants using specific microbial oxidoreductase enzymatic systems. Highly potential oxidoreductase derived from different microbes, plants, have been summarized to minimize the toxic effects of various toxic compounds. The book, therefore, seems to provide insight through different recent and eco-friendly approaches for waste management and offers the opportunity to minimize, reduce the effects of contaminants, and thereby attempting to reduce toxicological endpoints to ensure the safety of the environment.
\end{abstract}

Keywords: Bioremediation, Phytoremediation, Eco-friendly, Toxicity, Industrial pollutants

\footnotetext{
*Correspondence: araj@iitr.res.in

${ }^{1}$ Environmental Microbiology Laboratory, Environmental Toxicology

Group, CSIR-Indian Institute of Toxicology Research (CSIR-IITR), Vishvigyan

Bhawan, 31, Mahatma Gandhi Marg, Lucknow, Uttar Pradesh 226001,

India

Full list of author information is available at the end of the article
} adaptation, distribution and reproduction in any medium or format, as long as you give appropriate credit to the original author(s) and the source, provide a link to the Creative Commons licence, and indicate if changes were made. The images or other third party material in this article are included in the article's Creative Commons licence, unless indicated otherwise in a credit line to the material. If material is not included in the article's Creative Commons licence and your intended use is not permitted by statutory regulation or exceeds the permitted use, you will need to obtain permission directly from the copyright holder. To view a copy of this licence, visit http://creativeco mmons.org/licenses/by/4.0/. 


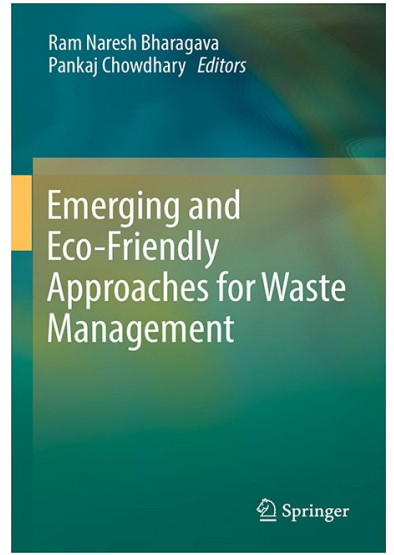

\section{Book details}

$\begin{array}{ll}\text { ISBN } & 978-981-10-8668-7, \text { ISBN } 978- \\ & 981-10-8669-4 \text { (eBook), } \\ \text { Doi } & \text { https://doi.org/10.1007/978-981- } \\ & \text { 10-8669-4, } \\ \text { Number of pages } & 443 \text { pages, Hard cover 129,99€ } \\ \text { Edited by } & \text { Ram Naresh Bharagava, Pankaj } \\ & \text { Chowdhary, } \\ \text { Published by } & \text { Springer, } \\ \text { Year } & 2018 .\end{array}$

\section{Introduction}

The broad range of pollutants, including halogenated phenol, phenolic compounds, PAHs, POPs, dioxins, chromium, heavy metals, and few other contaminants, are the main ingredients of wastewater discharged from the textile, pulp and paper, distillery, and tannery industries. A wide variety of contaminants that reside in untreated or partly treated wastewater have been reported to inflict significant harm in plant model organisms, animal models even in cell line-based studies. Industrial development and urbanization are emerging concerns that are detrimental to sustainability and environmental protection. Environmental contamination with a wide range of hazardous chemicals produced both naturally and anthropogenically (water, soil, and atmospheric) with detrimental impact on human and environmental. Potent research is expected to tackle and resolve these concerns to possible clean-up of such hazardous contaminants.

This book provides a comprehensive compilation of the various categories of toxic environmental contaminants that evolve and arise from several industrial, natural, and anthropogenic sources. The toxicological endpoints of such contaminants on human, environmental components, animals, and plants, have been explained along with their mitigation approaches in an eco-friendly way. Few other different remediation technologies like; the anaerobic ammonium oxidation (anammox), advanced oxidation processes (AOPs), membrane bioreactor (MBR), microbial-mediated biodegradation, phytoremediation, and phycoremediation also described for waste management emerged from various industrial sectors.

This book comprises 18 chapters that cover relevant, convenient, and accessible bioremediation insights for remediation of various contaminants from different industries, using different approaches. Therefore, in the current situation, it is a critical matter of environmental and human safety. Substantial scientific challenge has possibly been tackled in an eco-friendly way to minimize such contaminants. The presenting book review provides a comprehensive understanding of the critical aspects of emerging environmental contaminants that are emitted by a wide diversity of industries and anthropological practices. It has harmful or toxicological impacts on humans, plants, and animals, along with the adverse effects and biodegradation strategies, bioremediation through respective evolving, and eco-friendly strategies are a key feature of the book. Besides the toxicological impacts and conventional remediation strategies, this book also offers a comprehensive knowledge of different sorts of evolving and eco-friendly approaches for degradation of contaminants and detoxification, which is critically needed for the safety of the environment.

Bharagava and Chowdhary (editors) published this book that covers most of the emerging environmental concerns and waste management practices using various approaches in a preferred way. It is focused on responding to several critical environmental questions and concerns relevant to waste management. The contents of this book are feasible and practically applicable to management of waste management. Furthermore, no similar work in the field of waste management has previously been carried out in an eco-friendly manner. This is a well-structured and well-written book dedicated to waste management on the technical and scientific aspects of waste management utilizing various microbial enzyme-based, certain plant-based enzymes, and some advanced techniques. A total of 43 authors from prominent, well-recognized universities/institutions worldwide participated and contributed to this presented book. The chapters are of decent quality and cover the challenging issues from the tannery, pulp and paper, distillery, and textile industries together with the recent emerging techniques regard eco-friendly waste management approaches. 
First chapter of the book describes the organic pollutants, including phenolic, dyes, volatile organic compounds (VOCs), which are the vital contributors pollutants from various industries like; tannery, distillery, pulp and paper, and textile. Heavy usage of different chemicals in these industries also causes severe environmental harm due to the highly toxic nature of the chemical compounds [1]. Wastewaters from such industries are rich in chlorine residues, persistent organic pollutants (POPs), pesticides, and dioxins, which are liable to dark colors of wastewaters. For addressing and minimizing the concern pollutants, different bioremediation technologies have been described, like bioremediation, phytoremediation, constructed wetland $(\mathrm{CW})$, enzymatic based treatments, etc. Besides the bioremediation technologies, some emerging technologies are also described which include advanced oxidation process, photo-catalysis, membrane filtration, etc., and concluded with the merits and demerits [2].

Chapters 2, 6, and 7 provide an overview of emerging contaminants, like polycyclic aromatic hydrocarbons (PAHs), and endocrine-disrupting chemicals (EDCs); they may cause various adverse impacts such as alter the hormonal balance as well as breeding behavior of living beings, and ultimately liable to developmental deformities in human, animals as well [3]. These chapters also focus on the degradation and detoxification approaches of many other emerging contaminants. Nearly around 72 enterovirus serotypes have been isolated from different body parts; nevertheless, the only enterovirus affects humans since poliovirus is homologous to the numerous categories includes of rhinovirus, coxsackieviruses, and enterocytopathic groups. Various treatment approaches like ozonation, membrane filtration have discussed in this chapter for the mitigation of concerned contaminants [4].

Chapter 3 summarizes in detail different soil contaminants from municipal solid waste and their hazardous issues in industrializing nations. It also describes the applications of bioremediation and toxicity on the environment from municipal solid wastes from its contaminated soil, which is rich in a wide variety of different contaminants. The need to restore the contaminated site for municipal solid waste would be triggered. These techniques also discussed for the implementation of bioremediation processes with well-organized environmental safety assessment processes [5].

Chapter 4 is dedicated to industrial wastewater treatment using a submerged anaerobic membrane bioreactor (AnMBR). The anammox procedure is found to be a promising method for the removal of ammonia-rich wastewater nitrogen with a mix of low carbon to nitrogen. Anammox bioreactor has been described as dedicated to the treatment of synthetic wastewaters. The analysis has tested through an anammox submerged bioreactor that could be operated for about 150 days. Literature addressed the limitations of this procedure to clarify the potential of anammox bacteria to remove nitrogen from industrial wastewater. Several studies in this section stated that anaerobic membrane bioreactors (AnMBRs) were run under totally anaerobic supplied with the synthetic medium [6]. The study revealed that the efficiency of nitrogen removal at the low $\mathrm{COD} / \mathrm{NH} 4-\mathrm{N}$ ratio would be enhanced. An essential role of nitrogen removal efficiency is often demonstrated through prominent COD/ NH4-N.

Chapter 5 explores the respective impacts of waste from the distillery industry (DIs). It includes toxic, beneficial aspects, and treatment. The detailed description of toxicity caused by alcohol industries has been described in an explanatory manner. The wastewater of these industries is highly toxic as it causes genotoxicity as well as carcinogenic effects on living beings. Phytotoxicity on plant model organisms also described for describing the toxicological impacts of DWW. Apart from toxicological aspects, miscellaneous use of distillery wastewater also explained. Moreover, the treatment of distillery wastewater also described, along with the existing techniques. Besides the impacts and toxicity of distillery wastewater, diverse approaches of distillery wastewater are also summarized [7].

Chapter 6 explores the various bioremediation techniques for biodegradation and detoxification of PAHs. As a potent contaminant of the environment, the source of PAHs, their toxicological hazards and environmental problems are addressed in this section [8]. Apart from carcinogenic, mutagenic, and teratogenic properties, it affects the environment adversely and this has led to more attention and measures to minimize the toxicity, and remediation for environment safety. For addressing the environmental and human health concerns, various techniques for PAHs degradation have been summarized and dedicated primarily. Four potential plant species for phytodegradation are described for PAHs removal. The maximum PAHs removal with $81.5 \%$ of petroleum hydrocarbon within $73 \mathrm{~h}$ has been reported using Scirpus grossus. Five valuable species of fungal isolates also mentioned, which are involved in PAHs degradation. Six bacterial species also listed for degradation of naphthalene, fluorine with a degradation efficiency of $95 \%$ in 4 days (96 h.) treatment. Six species of algae for fluoranthene degradation reported with $99 \%$ efficiency in 7 days of treatment (168).

Chapter 7 is specially dedicated to EDCs (endocrinedisrupting chemicals), a chemical class that can impact the normal function of the human endocrine system, including those for animals [9]. All such compounds are 
widespread in different environments, including water, wastewater, sediments, and in atmosphere. A different source of EDCs and their presence in the environment are also discussed. Various industries include textile, pharmaceuticals, paper, tannery, and distillery are the potential emitting source of such compounds, which act as EDCs if exposed to humans and animals. Phthalates, alkylphenol ethoxylates (APEOs), bisphenol A (BPA), chlorophenols, and pesticides are among EDCs, which are released from different industrial sources. The impact of different EDCs is elaborated along with the removal of such compounds from wastewater using a potential bacterial system. Various bacterial species and their mediated biodegradation of EDCs have been summarized in detail for their removal from various industrial wastewaters [10].

Chapter 8 is dedicated to arsenic-mediated toxicity and its remediation strategies using different remediation techniques. Occurrence and source of AS and its toxicity profile have been described along with its remediation for minimizing its toxicity impacts that affect human health by causing several health conditions. Natural and anthropogenic sources are the key points of this chapter [11]. The toxicological effects of AS on humans have been summarized in detail, a total of 16 human physiological effects (including, reproductive, respiratory, immunological, pulmonary, cardiovascular, hematological, hepatic, renal, dermal, neurological, developmental, gastrointestinal, genotoxic, mutagenic, carcinogenic, and diabetes mellitus) have been elaborated in a systematic manner.

A total of 12 different (including, biosorption, bioaccumulation, bioreduction, biomethylation, biomineralization, phytoextraction, phytostabilization, phytoimmobilization, volatilization, rhizofiltration, phytoextraction, rhizodegradation) arsenic remediation techniques have been listed for a better understanding of reduction of arsenic-mediated toxicity exploiting the different remediation processes. Bacteria, algae, and plant-mediated arsenic bioremediation processes are described in detail along with genetically engineered microbes (GEM) as a dedicated part, with low cost and eco-friendly manner.

Chapter 9 emphasizes on microalgal based management of alcohol distillery wastewater. Its environmental impact and difficulties with its wastewater have been summarized. Open pond-based wastewater treatment systems for distillery wastewater, while the crucial part of this chapter are annular PBR units with Chlorella sorokiniana culture on expelled wastewater from alcohol distillery is described in detail [12].

Chapter 10 describes as emerging techniques for the bioremediation of various environmental pollutants using endophytes. In this section, a micro-organism community recognized as endophytes that have been evaluated for bioremediation of different pollutants [13]. Such micro-organisms are capable of reducing or minimizing the various heavy metals, dyes, and various environmental pollutants. Bio resourcing and mechanism of heavy metal removal are also explained systematically.

Chapter 11 focuses mainly on the toxicity and various remediation strategies in textile wastewater samples. The wastewater releases from the dye textile industry, which contains a large number of contaminants, including synthetic dyes, chemicals, and so on. Such wastewater is detrimental if it attains by aquatic bodies or flora and fauna even to the human being [14]. Biological treatment methods, along with some eco-friendly approaches, include; constructed wetland, bio-composting, windrow composting, aerated static pile, in-vessel composting, etc. are highly useful to mitigation or reducing the contaminants. A case study and its toxicological consequences of textile wastewater dyes have been reported and described in detail ("Toxic Sludge Irrigating Fields for 20 years").

Chapter 12 is dedicated to environmental concern arising from the pesticides, for example: pesticides and fungicidal, that affects human and other animals, hence, pose a significant health threats from such hazardous compounds. Even though this is factual, quite considerable use, along with applications of pesticides and their mediated toxicity, has been focused in this section. Various environmental pollutants, including DDT, PAHs, tetrachlorophenol, hydrocarbons, 2,4-dichlorophenoxyacetic acid, pentachlorophenol, trichloroethylene, and their bioremediation through phytoremediation employing different plants are mentioned concisely [15].

Chapter 13 facilitates extensive recent advances, various physicochemical characteristics, toxicity profile, and several physicochemical and biological wastewater treatment systems for the pulp and paper industry. Highly concentrated effluents of pulp \& paper industries reduce the texture of the soil, which is not only retarded seed growth; the depletion of aquatic systems also affects the whole aquatic ecosystem. For germination and vegetation, it inhibit overall plant physiology, obstructing in photosynthesis, and reduces the dissolved oxygen level (DO) level by causing toxicological effects in the aquatic system [16]. Therefore, this chapter provides comprehensive details about the sources, impact, toxicity, and physicochemical characteristics, including biological treatment, approaches for pulp and paper mills, wastewater. For wastewater treatment of pulp and paper mill there are eight bacterial species, nine fungal species, and three algal species that have been described for enhanced wastewater treatment [17]. Bioreactor and some other advanced techniques also summarized for the treatment of wastewaters from paper and pulp industries. 
In chapter 14 , the primary emphasis is on plant-based remediation with wild and transgenic plants recognized as phytoremediation are the critical part of this chapter. Rhizosphere concerned for the elimination of heavy metal from polluted sites, including endophytic bacteria. Source of heavy metal, toxicity, and their hazards on humans and animals. Nine plant growth-promoting rhizobacteria (PGPR) has been enumerated for enhanced phytoremediation efficiency for heavy metal. Fourteen plant species and several of their associated bacteria are the key highlights of this section. Several transgenic plants also described for mitigation of heavy metal [17].

Chapter 15 describes the potentiality of peroxidases enzymes, which are extracted, and purified from numerous specific plants, including; turnip, seed coat of soybean, horseradish, pointed gourd, white radish, and some specific microbial species. Such plant-based approaches are regarded as eco-friendly approaches, and the same has been utilized for the removal of different phenolic contaminants that have been emphasized in this chapter [18]. Plant-based peroxidases or naturally occurred plants are the primary producers of peroxidases and their implementation in peroxidase immobilization also discussed as a potential application. Various methods for treating phenolic contaminants were developed in batch and continuous reactors for industrial wastewater with the use of such plant-based peroxidases. The significant part of this section is immobilized peroxidase for phenolic compounds removal. Elimination of phenolic pollutants has been reported in detail dedicated to environmental safety, deploying various peroxidase, immobilization of peroxidase from the gourd, seed coat, from soybean, turnip, and some other plant species along with microbial peroxidase [19].

Chapter 16 emphasizes on industrial nanoparticles production and diverse application of nanotechnology. Nanotechnology has the potential to generate NPs costeffectively promoting the environment both using these materials to recognize, avoid and eradicate contamination directly and by using nanotechnology to design cleaner industrial routes and to generate environmentally accountable products. Nanoparticles have been described as an evolving strategy for diverse environmental pollutant mitigation. Synthesizing nanoparticles by chemical, biological, and other several methods also explained. Characterization and application of nanoparticles in environmental waste management are focus point of this chapter. The role of synthesis nanoparticles and their role in organic pollutant removal are described in detail [20].

Chapter 17 defines the innovative treatment methods using biphasic methodologies to eliminate pollutants from industrial wastewater. Different biphasic treatment processes, such as liquid-liquid two-phase and solid-liquid partitioning, have been conclusively demonstrated successfully for the treatment of effluents from synthetic dyes, heavy metals, environmental pollutants, pharmaceutical ingredients, xenobiotic compounds, etc. Various biphasic systems are the focus of this chapter for the elimination of municipal runoff of the toxic and hazardous compounds. Organic contaminants, pharmaceutical ingredients, distillery effluent, textile effluents, and their treatment, together with the removal of heavy metals, are highlighted in detail, and systematically recognized as phycoremediation [21].

Chapter 18 concentrates primarily on phycoremediation technologies and its diverse remediation capabilities along with environmental sustainability advantages. The accumulation of inorganic and organic contaminants includes; pesticides, herbicides, insecticide, PCBs, DDT, and metals in the marine ecosystem together with metalloids that can cause lethal effects on the environment and organisms has been addressed in detailed [22]. Algae are well-known to be widely distributed on earth and adapted to different habitats. The remarkable aspect of its rapid adaptation helps the algae to grow in a diverse variety of environmentally suited for wastewater treatment and production of biofuel and other value-added products, including food, feed, fertilizer, pharmaceuticals, and, biofuel, etc.

Few other modern trends, and the absence of these aspects (modern trends) for wastewater treatment, including in silico approaches, highlight a negative part of this book. However, it might be much excellent if all these elements were applied to it.

The present book could be better in a much deeper understanding of the mitigation of the environmental contaminants if a few chapters were added to it covering the in silico technologies or approaches. Computational or in silico methods are the emerging trends and widely being used in bioremediation. Molecular docking, molecular dynamics simulation, homology modeling, and biodegradation pathways prediction are the crucial techniques that are the lack in this book. Additionally, environment conservation and ethics in waste management also must be incorporated and updated in the next edition. Besides ignorance of these points, the above book may be suggested to a variety of professionals, scientists, students, researchers, etc. having interests in bioremediation technologies in an eco-friendly manner.

Moreover, this book further encourages the basic and specialized understanding of environmental issues among researchers, scientists, and academics engaged in microbiology, biotechnology, and environmental sciences. Readers may often obtain useful information/ greater awareness about environmental aspects and remedies. 


\section{Acknowledgements}

We thank the editors, for the book to be read and reviewed. AKS would like to thank "AcSIR" -Ghaziabad, and funding agency "University Grant Commission" -New Delhi, India. The Director of CSIR-IITR and Council of Scientific \& Industrial Research also acknowledged. Author AR acknowledges Department of Biotechnology (DBT), Government of India, New Delhi, for supporting this work (Grant No. BT/PR20460/BCE/8/1386/2016). This manuscript no (CSIR-IITR, manuscript communication record) is 3602

\section{Authors' contributions}

Author AKS wrote overall manuscript and proofread, corrected and edited for language to initialy finalize this manuscript, AR final checked, proofread and finalized the manuscript for publishing. Both authors read and approved the final manuscript.

\section{Funding}

Not applicable.

\section{Availability of data and materials}

Not applicable.

\section{Ethics approval and consent to participate}

Both authors followed ethics and consented to participate in this manuscript.

\section{Consent for publication}

Both authors (AKS, AR) agreed and consented for publishing this manuscript.

\section{Competing interests}

No conflict of interest exists, declared by authors.

\section{Author details}

${ }^{1}$ Environmental Microbiology Laboratory, Environmental Toxicology Group, CSIR-Indian Institute of Toxicology Research (CSIR-IITR), Vishvigyan Bhawan, 31, Mahatma Gandhi Marg, Lucknow, Uttar Pradesh 226001, India. ${ }^{2}$ Academy of Scientific and Innovative Research (AcSIR), Ghaziabad 201002, India.

Received: 12 May 2020 Accepted: 24 July 2020

Published online: 17 August 2020

\section{References}

1. Bianco B, De Michelis I, Vegliò F (2011) Fenton treatment of complex industrial wastewater: optimization of process conditions by surface response method. J Hazard Mater 186(2-3):1733-1738

2. Chandra R, Chowdhary P (2015) Properties of bacterial laccases and their application in bioremediation of industrial wastes. Environ Sci Process Impacts 17(2):326-342

3. Hu D-P et al (2016) Actions of estrogenic endocrine disrupting chemicals on human prostate stem/progenitor cells and prostate carcinogenesis. Open Biotechnol J 10(1):76-96. https://doi.org/10.2174/1874070701 610010076

4. Koumaki E et al (2015) Degradation of emerging contaminants from water under natural sunlight: the effect of season, $\mathrm{pH}$, humic acids and nitrate and identification of photodegradation by-products. Chemosphere 138:675-681
5. Brito EM et al (2015) Impact of hydrocarbons, PCBs and heavy metals on bacterial communities in Lerma River, Salamanca, Mexico: investigation of hydrocarbon degradation potential. Sci Total Environ 521:1-10

6. Mostafa MG (2012) Recent advances in anammox bioreactors for industrial wastewater reuse. J Pet Environ Biotechnol. 3(5):108

7. Christofoletti CA et al (2013) Sugarcane vinasse: environmental implications of its use. Waste Manag 33(12):2752-2761

8. Haritash A, Kaushik CP (2009) Biodegradation aspects of polycyclic aromatic hydrocarbons (PAHs): a review. J Hazard Mater 169(1-3):1-15

9. Cases $V$ et al (2011) Endocrine disrupting compounds: a comparison of removal between conventional activated sludge and membrane bioreactors. Desalination 272(1-3):240-245

10. Danzl E et al (2009) Biodegradation of bisphenol A, bisphenol F and bisphenol S in seawater. Int J Environ Res Public Health 6(4):1472-1484

11. Zouboulis Al, Katsoyiannis IA (2005) Katsoyiannis, Recent advances in the bioremediation of arsenic-contaminated groundwaters. Environ Int $31(2): 213-219$

12. Alcántara C et al (2015) Mixotrophic metabolism of Chlorella sorokiniana and algal-bacterial consortia under extended dark-light periods and nutrient starvation. Appl Microbiol Biotechnol 99(5):2393-2404

13. Guo H et al (2010) Bioremediation of heavy metals by growing hyperaccumulator endophytic bacterium Bacillus sp. L14. Bioresour Technol 101(22):8599-8605

14. Bizuneh A (2012) Textile effluent treatment \& decolorization techniques. Chem Bulg J Sci Educ 21:434-456

15. Andreu V, Picó Y (2004) Determination of pesticides and their degradation products in soil: critical review and comparison of methods. TrAC Trends Anal Chem 23(10-11):772-789

16. Ashrafi O, Yerushalmi L, Haghighat F (2015) Wastewater treatment in the pulp-and-paper industry: a review of treatment processes and the associated greenhouse gas emission. J Environ Manag 158:146-157

17. Malaviya P, Rathore VS (2007) Bioremediation of pulp and paper mill effluent by a novel fungal consortium isolated from polluted soil. Bioresour Technol 98(18):3647-3651

18. Alemzadeh I, Nejati S (2009) Phenols removal by immobilized horseradish peroxidase. J Hazard Mater 166(2-3):1082-1086

19. Dahili LA, Kelemen-Horváth I, Feczkó T (2015) 2, 4-Dichlorophenol removal by purified horseradish peroxidase enzyme and crude extract from horseradish immobilized to nano spray dried ethyl cellulose particles. Process Biochem 50(11):1835-1842

20. Hitkari G, Singh S, Pandey G (2019) Nanoparticles: an emerging weapon for mitigation/removal of various environmental pollutants for environmental safety. In: Emerging and Eco-Friendly Approaches for Waste Management. Springer, Singapore, pp 359-395

21. Taghavivand M, Pazuki G (2014) A new biocompatible gentle aqueous biphasic system in cefalexin partitioning containing nonionic Tween 20 surfactant and three organic/inorganic different salts. Fluid Phase Equilibr 379:62-71

22. McGrath SP, Zhao FJ (2003) Phytoextraction of metals and metalloids from contaminated soils. Curr Opin Biotechnol 14(3):277-282

\section{Publisher's Note}

Springer Nature remains neutral with regard to jurisdictional claims in published maps and institutional affiliations. 